\title{
Vasoactive Intestinal Peptide in Early Spondyloarthritis: Low Serum Levels as a Potential Biomarker for Disease Severity
}

\author{
Iria V. Seoane • Eva Tomero • Carmen Martínez • Rosario Garcia-Vicuña • \\ Yasmina Juarranz • Amalia Lamana • Elena Ocón • Ana M. Ortiz • \\ Nieves Gómez-León • Isidoro González-Álvaro • Rosa P. Gomariz
}

Received: 12 January 2015 / Accepted: 4 February 2015 / Published online: 25 February 2015

(C) The Author(s) 2015. This article is published with open access at Springerlink.com

\begin{abstract}
Spondyloarthritis (SpA) is a family of inflammatory diseases sharing clinical, genetic, and radiological features. While crucial for tailoring early interventions, validated prognostic biomarkers are scarce in SpA. We analyze the correlation between serum levels of vasoactive intestinal peptide (VIP) and disease activity/severity in patients with early chronic inflammatory back pain. The study population comprised 54 patients enrolled in our early chronic inflammatory back pain register. We collected demographic information, clinical data, laboratory data, and imaging findings. VIP levels were measured by enzyme immunoassay in serum samples from 162 visits. The association between independent variables and VIP levels was analyzed using longitudinal multivariate analysis nested by patient and visit. No significant differences were observed in VIP levels between these two groups. Lower levels of VIP were significantly associated
\end{abstract}

Isidoro González-Álvaro and Rosa P. Gomariz share senior authorship.

Iria V. Seoane and Eva Tomero contributed equally to this work.

I. V. Seoane $\cdot$ Y. Juarranz $\cdot$ R. P. Gomariz $(\bowtie)$

Departamento de Biología Celular, Facultad de Biología,

Universidad Complutense de Madrid, Antonio Novais, no. 2, Ciudad

Universitaria, 28040 Madrid, Spain

e-mail: gomariz@bio.ucm.es

E. Tomero $\cdot$ R. Garcia-Vicuña $\cdot$ A. Lamana $\cdot$ A. M. Ortiz $\cdot$

I. González-Álvaro $(\bowtie)$

Servicio de Reumatología, Hospital Universitario de la Princesa, Instituto de Investigación Sanitaria la Princesa, Madrid, Spain

e-mail: isidoro.ga@ser.es

C. Martínez

Departamento de Biología Celular, Facultad de Medicina,

Universidad Complutense de Madrid, Madrid, Spain

E. Ocón • N. Gómez-León

Servicio de Radiodiagnóstico, Hospital Universitario de la Princesa, Instituto de Investigación Sanitaria la Princesa, Madrid, Spain with a higher Bath Ankylosing Spondylitis Disease Activity Index (BASFI) score, presence of bone edema in magnetic resonance imaging (MRI) scan, and lower hemoglobin levels. Coexistence of cutaneous psoriasis was independently associated with lower VIP levels, and similar trend was observed for enthesitis. We conclude that SpA patients with low serum VIP levels had worse 2-year disease outcome, suggesting that serum VIP levels could be a valid prognostic biomarker.

Keywords Neuroimmunomodulation · Spondyloarthritis . Vasoactive intestinal peptide $\cdot$ Prognosis biomarker $\cdot$ Bath Ankylosing Spondylitis Disease Activity Index

\section{Introduction}

Spondyloarthritis (SpA) is a family of interrelated rheumatic diseases that share clinical and radiological manifestations; the most prevalent and paradigmatic member of the group is ankylosing spondylitis (Dougados and Baeten 2011). SpA comprises a wide variety of skeletal and extra-skeletal phenotypes that are associated with the presence of the HLA-B27 antigen, which accounts for familial association and can explain recent hallmark findings on pathogenesis (Colbert et al. 2010). Compared with joint involvement in rheumatoid arthritis (RA), inflammation in SpA mainly takes the form of enthesitis and commonly results in bone formation and ankylosis rather than bone erosion (Marzo-Ortega et al. 2002; McGonagle et al. 2014). Nevertheless, the consequences of these changes also lead to functional limitations, poor quality of life, loss of working hours, and even decreased life expectancy (Braun and Pincus 2002; Fabreguet et al. 2012). Prognosis is often poorer because of the delay in 
diagnosis, especially in patients with isolated axial involvement (Rudwaleit et al. 2005). This was particularly true until 5-10 years ago, when diagnosis could only be confirmed based on radiological damage (van der Linden et al. 1984). New classification criteria enable SpA to be diagnosed before radiologic evidence of disease is available (Rudwaleit et al. 2009b), and magnetic resonance imaging (MRI) now plays a key role in the early identification of patients with SpA (Bennett et al. 2009). Nonetheless, diagnosis of non-radiologic $\mathrm{SpA}$ remains a challenge, since, in most cases, the first manifestation is low back pain, a common complaint in the general population (Carmona et al. 2001; Deyo and Weinstein 2001).

Biologics, mainly TNF blockers, are the second major advance in the management of SpA (Machado et al. 2013). However, given the considerable heterogeneity in the clinical manifestations of these disorders, ranging from self-limiting to chronic severe and progressive forms (Dougados and Baeten 2011), and concerns over safety and cost, the use of TNF blockers should be restricted to patients with an optimal risk-benefit ratio. Prognostic markers such as C-reactive protein (CRP) levels, smoking, HLA-B27 positivity, and structural damage at diagnosis have been associated with progression of radiological damage (Chung et al. 2012; MarzoOrtega et al. 2009; Poddubnyy et al. 2012); however, validated biomarkers for predicting progression are lacking and early detection of candidates for TNF blockade remains difficult.

Vasoactive intestinal peptide (VIP) is a molecule of the neuroendocrine-immune network with demonstrated immunoregulatory properties (Gomariz et al. 2006; Leceta et al. 2007). Treatment with VIP has been shown to reduce the severity of arthritis in murine models (Delgado et al. 2001; Juarranz et al. 2005) and improves the course of other inflammatory models in mice (Abad et al. 2003; Jimeno et al. 2010; Li et al. 2006; Lodde et al. 2006). In human assays, in vitro use of VIP regulated differentiation of $\mathrm{T}$ cells, modulated the balance of proinflammatory and anti-inflammatory cytokines (Gutierrez-Canas et al. 2008), and decreased expression of several proinflammatory pathways in synovial fibroblasts (Carrion et al. 2011, 2014; Gutierrez-Canas et al. 2006). We recently reported that early arthritis patients with low baseline serum VIP levels have a more severe disease course and require more intensive treatment with disease-modifying anti-rheumatic drugs (DMARDs) (Martinez et al. 2014). In addition, reduced VIP expression has been observed in the synovial fluid of osteoarthritis patients with a poorer disease course (Jiang et al. 2012). The aim of this study, therefore, was to elucidate the potential role of VIP serum levels as a biomarker of severity in early inflammatory back pain.

\section{Material and Methods}

\section{Ethics Statement}

The register protocol for the early chronic inflammatory back pain (CIBP) clinic at Hospital Universitario La Princesa was reviewed and approved by the Ethics Committee for Clinical Research at Instituto de Investigación Sanitaria La Princesa. Consecutive patients who attended the early CIBP clinic from June 2010 to June 2013 were recruited. All patients were informed about the study and signed an informed consent form before their inclusion in the register.

\section{Patients}

The study sample comprised 54 patients from the register. The inclusion criteria are inflammatory back pain (IBP) for more than 3 months and less than 2 years, and symptom onset before age 45 years.

The register protocol comprised three prospective visits (baseline, 1 and 2 years). The data recorded at baseline include gender, age, ethnicity, and educational and occupational status. At each visit, we systematically collect clinical and laboratory data, as follows: date of onset of IBP, specific features of SpA (enthesitis, arthritis, uveitis, psoriasis, and inflammatory bowel disease), previous infections and family history of SpA. Patients were asked to complete the Bath Ankylosing Spondylitis Disease Activity Index (BASDAI) (Garrett et al. 1994) and Bath Ankylosing Spondylitis Functional Index (BASFI) (Calin et al. 1994). The laboratory parameters recorded include HLA-B27 positivity, CRP levels, erythrocyte sedimentation rate (ESR), alkaline phosphatase (ALP), and hemoglobin $(\mathrm{Hb})$ among other parameters. In addition, serum samples were taken and stored at $-80^{\circ} \mathrm{C}$. Radiographs of the sacroiliac joints and the cervical and lumbar spine (lateral view) were taken at every visit. Radiological sacroiliitis was defined according to the modified New York criteria (van der Linden et al. 1984). MRI of the sacroiliac joints is performed at baseline to assess the presence of the active inflammatory lesions (bone marrow edema) according to the Assessment of SpondyloArthritis international Society (ASAS)/Outcome Measures in Rheumatology (OMERACT) definition (Rudwaleit et al. 2009a).

Information related to the treatment established for each patient (DMARDs, nonsteroidal anti-inflammatory drugs [NSAIDs], biologic agents, and/or corticosteroids) is also recorded. The data were entered into an electronic database.

Of the 54 patients initially enrolled, 37 were diagnosed with $\mathrm{SpA}$ based on the rheumatologist's clinical judgment, 34 fulfilled the ASAS criteria for SpA (Rudwaleit et al. 2009b) and 13 the New York criteria for ankylosing spondylitis (van der Linden et al. 1984). After 2 years of follow-up, the 17 patients who did not satisfy the criteria for a diagnosis 
of $\mathrm{SpA}$ were considered to have non-specific chronic low back pain (NLBP).

\section{Measurement of Serum VIP Level}

VIP levels were assessed using a commercially available competitive enzyme-linked immunosorbent assay (ELISA) kit (Phoenix Pharmaceuticals, Karlsruhe, Germany). Briefly, the serum samples were freeze-dried and dissolved in ELISA buffer $(2: 1)$, added to an immunoplate coated with a secondary antibody, and incubated with biotinylated VIP and a primary antibody whose Fab fragment was competitively bound by both biotinylated peptide and targeted peptide in samples. After washes, we added streptavidin-horseradish peroxidase to each well. During this incubation, the enzyme catalyzed the oxidation of the substrate solution. We terminated the enzymatic reaction using a stop solution and measured absorbance at $450 \mathrm{~nm}$. A standard curve of known concentration was established. The concentration of VIP in the samples was determined by extrapolation to this standard curve and application of the corresponding dilution factor. Samples from each patient were assayed twice. The minimum detectable concentration was $0.12 \mathrm{ng} / \mathrm{ml}$, with an intra-assay and interassay variation of $\leq 5$ and $15 \%$, respectively. We previously reported that there was no significant correlation between VIP serum level and frozen time (Martinez et al. 2014).

\section{Statistical Analysis}

Normally distributed quantitative variables were represented as the mean \pm standard deviation (SD), while non-normally distributed variables were represented as the median and interquartile range (IQR). Variables with a normal distribution were analyzed using the $t$ test; variables with a non-normal distribution were analyzed using the Mann-Whitney test or Kruskal-Wallis test. Categorical variables were expressed as percentages and significance levels between groups were established using the $\chi^{2}$ test or the Fisher exact test.

In order to better determine the association between heterogeneity in serum VIP levels and clinical variables, we fitted a population-averaged model by means of generalized linear models nested by patient and visit using the xtgee command of Stata 12 for Windows (StataCorp LP, College Station, TX, USA). Since the raw variable serum VIP level did not show a Gaussian distribution, data were normalized through logarithmic transformation. Variables displaying a $p$ value $<0.15$ in the bivariate analysis were included in the multivariate analysis. Age and sex were included because previous studies had shown that these variables can act as confounders (Martinez et al. 2014). In addition, considering the interassay variability of ELISA, the model was also adjusted for the variations in assay plate VIP levels. Thereby, the final models were constructed using the quasi-likelihood under the independence model information criterion and the Wald test (Pan 2001) after removing all variables with a $p$ value above 0.15 .

\section{Results}

\section{Characteristics of Patients with Early $\mathrm{SpA}$}

The study population comprised 54 patients with either SpA $(n=37)$ or NLBP $(n=17)$. Table 1 shows the characteristics of the patients at baseline. The main differences between the two groups were that those diagnosed with $\mathrm{SpA}$ more often had a family history of SpA, HLA-B27 positivity, inflammation, structural damage in the sacroiliac MRI scan or radiographs, higher PCR levels, and lower levels of hemoglobin than patients with NLBP. However, no significant differences between these groups were detected for the functional indices, disease activity, or other laboratory variables (Table 1).

No significant differences were detected in serum VIP levels between SpA patients and NLBP patients at baseline $(p=0.36)$ (Table 1). In addition, no relevant variation in VIP levels was observed during follow-up in either patient subset. We observed a non-significant trend toward increased VIP levels with age (data not shown), as we had reported previously in RA patients (Martinez et al. 2014). However, we did not observed significant differences by gender (data not shown), opposite to what we had observed in RA patients (Martinez et al. 2014).

\section{Low Serum VIP Levels are Associated with Different} Features of $\mathrm{SpA}$

The BASDAI and BASFI scores were associated with serum VIP levels in the bivariate analysis, although only BASFI maintained this association in the multivariate analysis (Table 2). Patients with lower VIP levels had significantly higher BASFI scores (Fig. 1a), which indicate more severe disability. In addition, patients with inflammation on the MRI scan also had lower serum levels of VIP (Fig. 1b). This association was significant and independent in the multivariate analysis (Table 2). Furthermore, hemoglobin, which is associated with disease activity, was also significantly associated with serum VIP levels (Table 2 and Fig. 1c).

The presence of enthesitis or cutaneous psoriasis was also independently associated with lower serum VIP levels (Table 2, Fig. 2).

Only two patients in our study had inflammatory bowel disease; a non-significant trend toward lower levels of VIP was observed in both (data not shown). By contrast, patients who had experienced uveitis displayed significantly higher levels of VIP (Table 2). 
Table 1 Baseline characteristics of patients with spondyloarthritis or chronic low back pain

\begin{tabular}{|c|c|c|c|c|}
\hline & Spondyloarthritis $(n=37)$ & Low back pain $(n=17)$ & Total $(n=54)$ & $p$ value \\
\hline Age* (years) & $35.8 \pm 10.7$ & $40.8 \pm 9.7$ & $37.5 \pm 10.6$ & 0.09 \\
\hline Gender** (female) & $25(67.6)$ & $8(47.1)$ & $33(61)$ & NS \\
\hline Ethnicity** (Caucasian) & $26(70.3)$ & $12(70.6)$ & $38(70.4)$ & NS \\
\hline Family history of $\mathrm{SpA} * *$ & $14(37.8)$ & $1(5.9)$ & $15(27.8)$ & 0.015 \\
\hline HLA-B27 $(+)^{* *}$ & $21(56.7)$ & $3(17.7)$ & $24(44.4)$ & 0.007 \\
\hline Enthesitis** & $16(43.2)$ & $3(17.7)$ & $19(35.2)$ & 0.067 \\
\hline Arthritis** & $11(29.7)$ & $1(5.9)$ & $12(22.2)$ & 0.05 \\
\hline Uveitis** & $3(8.1)$ & $1(5.9)$ & $4(7.4)$ & NS \\
\hline Psoriasis** & $4(10.8)$ & $1(5.9)$ & $5(9.3)$ & NS \\
\hline $\mathrm{IBD} * *$ & $2(5.4)$ & $0(0.0)$ & $2(3.7)$ & NS \\
\hline Previous infections $* *$ & $3(8.1)$ & $0(0.0)$ & $3(5.6)$ & NS \\
\hline Sacroiliitis MRI** & $22(59.5)$ & $0(0.0)$ & $22(40.7)$ & $<0.001$ \\
\hline Sacroiliitis X-ray** & $12(33.3)$ & $0(0.0)$ & $12(22.2)$ & NS \\
\hline BASDAI* & $40.5 \pm 23.1$ & $36.4 \pm 22.9$ & $39.4 \pm 22.7$ & NS \\
\hline $\mathrm{BASFI}^{* * *}$ & $29[12-45]$ & $25.5[11-50]$ & $26[12-45]$ & NS \\
\hline $\mathrm{CRP}(\mathrm{mg} / \mathrm{dl}) *$ & $0.99 \pm 2.3$ & $0.2 \pm 0.25$ & $0.7 \pm 0.2$ & 0.048 \\
\hline $\operatorname{ESR}(\mathrm{mm} / \mathrm{h})^{*}$ & $23.3 \pm 18.8$ & $15.6 \pm 13.0$ & $21.0 \pm 17.5$ & 0.082 \\
\hline $\operatorname{ALP}(\mathrm{U} / \mathrm{l})^{*}$ & $62.8 \pm 19.4$ & $67.2 \pm 18.2$ & $64.2 \pm 18.9$ & NS \\
\hline $\mathrm{Hb}(\mathrm{g} / \mathrm{dl})^{*}$ & $13.2 \pm 2.4$ & $14.6 \pm 1.3$ & $13.6 \pm 2.2$ & 0.023 \\
\hline $\mathrm{VIP}(\mathrm{pg} / \mathrm{ml})^{* * *}$ & $250[209-280]$ & 292 [230-337] & $251[212-303]$ & NS \\
\hline
\end{tabular}

Data are shown as the mean \pm standard deviation (SD), frequency $n(\%)$, or median and [interquartile range]

$I B D$ inflammatory bowel disease, MRI magnetic resonance imaging, BASDAI Bath Ankylosing Spondylitis Disease Activity Index, BASFI Bath Ankylosing Spondylitis Functional Index, $C R P$ C-reactive protein, ESR erythrocyte sedimentation rate, $A L P$ alkaline phosphatase, $H b$ hemoglobin, $V I P$ vasoactive intestinal peptide, $N S$ non-significant

Statistical significance was established by * Student's $t$ test, ${ }^{* *} \chi^{2}$ or $* * *$ Kruskal-Wallis test for a $p$ value $<0.05$

In order to determine how robust these results were, we also perform a multivariate analysis restricted to the SpA patients group. Most associations remain similar as those described herein (Table 3).

Table 2 Multivariate analysis of variables associated with VIP serum levels

\begin{tabular}{llll}
\hline & $\beta$ Coeff. \pm SE & CI $(95 \%)$ & $p$ value \\
\hline Enthesitis & $-0.104 \pm 0.058$ & -0.217 to 0.010 & 0.075 \\
Uveitis & $0.383 \pm 0.106$ & 0.176 to 0.591 & $<0.001$ \\
Psoriasis & $-0.227 \pm 0.094$ & -0.411 to -0.044 & 0.015 \\
Sacroiliitis MRI & $-0.150 \pm 0.057$ & -0.262 to -0.038 & 0.009 \\
Biological therapy & $0.184 \pm 0.118$ & -0.048 to 0.417 & 0.120 \\
BASFI & $-0.003 \pm 0.001$ & -0.005 to -0.001 & 0.003 \\
Hb $(\mathrm{g} / \mathrm{dl})$ & $0.031 \pm 0.012$ & 0.006 to 0.055 & 0.014 \\
\hline
\end{tabular}

Results of multivariate analysis performed with data from SpA patients and NLBP patients. Only variables with $p$ value $<0.15$ in the respective bivariate analysis were included. Variables with $p$ value $<0.15$, in the respective bivariate analysis, that were not included in the final model of the multivariate analysis are as follows: age, family history of SpA, HLA-B27(+), arthritis, CRP, and ESR

$\beta$ Coeff. $\beta$ coefficient of Wald test, SE standard error, $C I$ confidence interval
Finally, only three patients required TNF blockers during follow-up, and we observed a non-significant trend toward higher levels of VIP after TNF blockade (data not shown). No significant association was observed with the prescription of DMARDs (sulfasalazine and methotrexate).

\section{Discussion}

We provide the first evidence of the association between low serum VIP levels and increased disease severity in patients with early SpA, namely, impaired functional status, bone edema in MRI, and a more intense inflammatory burden (anemia, psoriasis, IBD, and enthesitis). Our results provide additional support to in vitro and animal models by reinforcing the role of VIP as a major regulator of the immune system in autoimmune diseases (Gomariz et al. 2006; Gutierrez-Canas et al. 2008).

Although a previous study had described higher levels of serum VIP in ankylosing spondilitis patients compared to healthy donors (Nalbant et al. 2011), our results showed no differences between $\mathrm{SpA}$ and nonspecific low back pain patients. Possible explanations for this divergence are differences between both populations in gender distribution, race, 
A
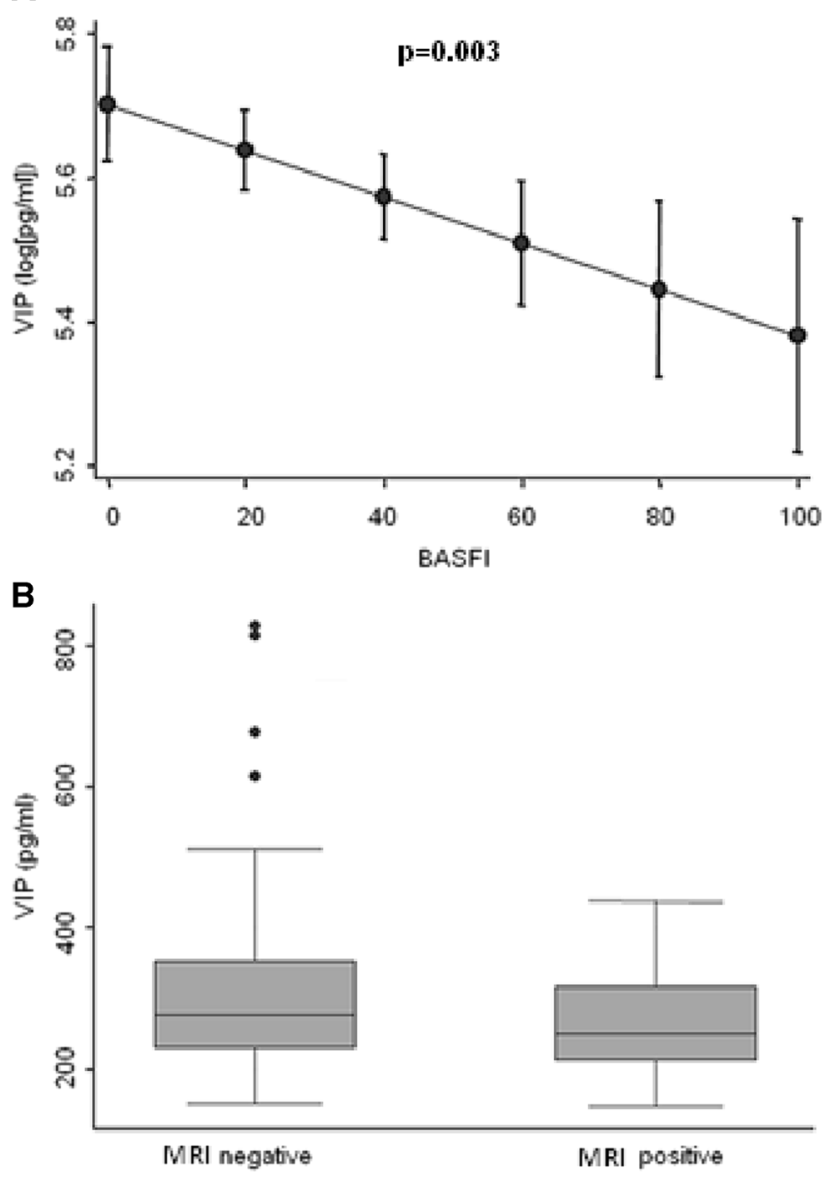

C

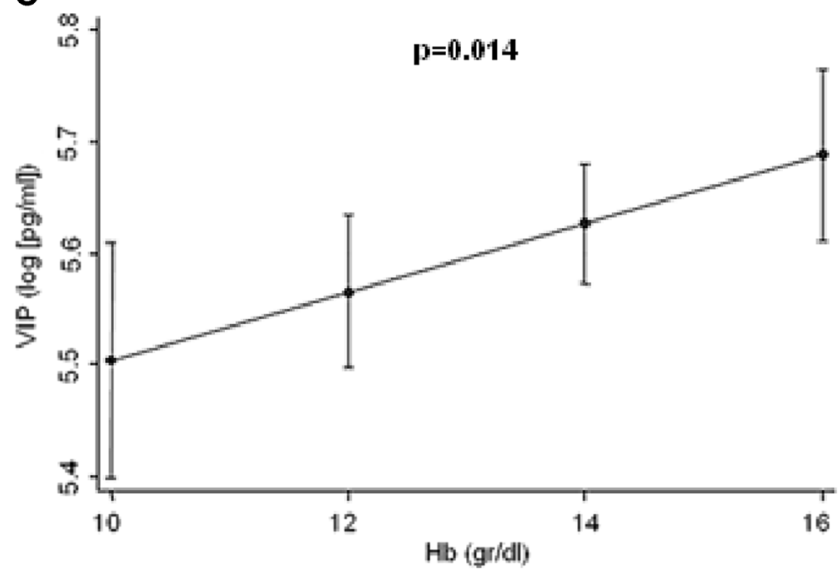

selection of controls, and early versus long-term disease stage. In addition, our findings are consistent with those of our previous observation that patients with early arthritis and low VIP serum levels have a more severe disease course (Martinez et al. 2014). Although variability in the VIP gene has not been reported as a genetic trigger of autoimmune disorders, several findings raise the possibility that once the disease has developed, low expression of VIP could lead to poorer outcome (Jiang et al. 2012; Martinez et al. 2014).
Fig. 1 Correlation between VIP serum levels during follow-up and clinical, radiological, and analytical variables. a Correlation between serum VIP levels during follow-up and the BASFI score. Data are shown as the mean value of VIP (normalized by logarithmic transformation) for each BASFI value adjusted for the other variables included in the multivariate analysis (solid dot). The figure also shows the $95 \%$ confidence interval (lines above and below the dot). b Association between VIP levels and radiological variables. Distribution of VIP serum levels of the study cohort based on the presence or absence of lesions associated with spondylitis on MRI. Data are represented as the interquartile range (p75 upper edge of the box, p25 lower edge, p50 midline), as well as the p90 (line above the box) and p10 (line below the box) of the serum VIP levels. Dots represent outliers. This figure illustrates the association between VIP serum levels and MRI findings shown at Table 2 where statistical significance is reported. c Association between VIP levels and hemoglobin levels. Data are shown as the mean value of VIP (normalized by logarithmic transformation) for each value of hemoglobin $(\mathrm{Hb})$ adjusted for the other variables included in the multivariate analysis (solid dot) and the $95 \%$ confidence interval (lines above and below the dot). a, b The values were estimated using the margins command of Stata 12, following a multivariate analysis for longitudinal data nested by visit and patient using the xtgee command

One of the various unmet needs in SpA is the availability of reliable biomarkers both to distinguish inflammatory back pain from the more prevalent mechanical pain and to determine prognosis (Almodovar et al. 2014; de Vlam 2010). New ASAS diagnostic criteria and increased use of MRI have mitigated previous diagnostic limitations, although clinicians still need tools to predict disease activity and progression or to decide which patients would benefit from biologic therapies. In this context, measurement of serum VIP levels could be a useful tool for detecting a subpopulation with a greater functional and inflammatory burden.

Our results raise the question of why BASFI, instead of BASDAI, was associated with low VIP levels in the multivariate analysis. Each index correlated well with the other, especially in early disease, although they have the disadvantage of focusing only on the patient's perspective (Ward et al. 2013). Bearing in mind that other objective measures of disease activity such as MRI findings or hemoglobin levels were included in the multivariate analysis, it can be assumed that BASDAI did not provide additional information to the statistical model (Kiltz et al. 2012; Machado et al. 2012). In fact, it is well known that functional limitation at diagnosis is associated with a worse prognosis of SpA (Landewe et al. 2009). Therefore, the negative correlation between serum VIP levels and evolution of BASFI during follow-up is an interesting finding, since predicting long-term disability remains a challenge in patients with early SpA.

The association between low serum VIP levels and extraarticular features of $\mathrm{SpA}$, such as psoriasis and enthesitis, further suggests the role of VIP as a biomarker of severity, since both impair quality of life and increase treatment requirements. In addition, VIP levels in the two patients with inflammatory low back pain and IBD were below the median VIP concentration in the whole population, although the difference 


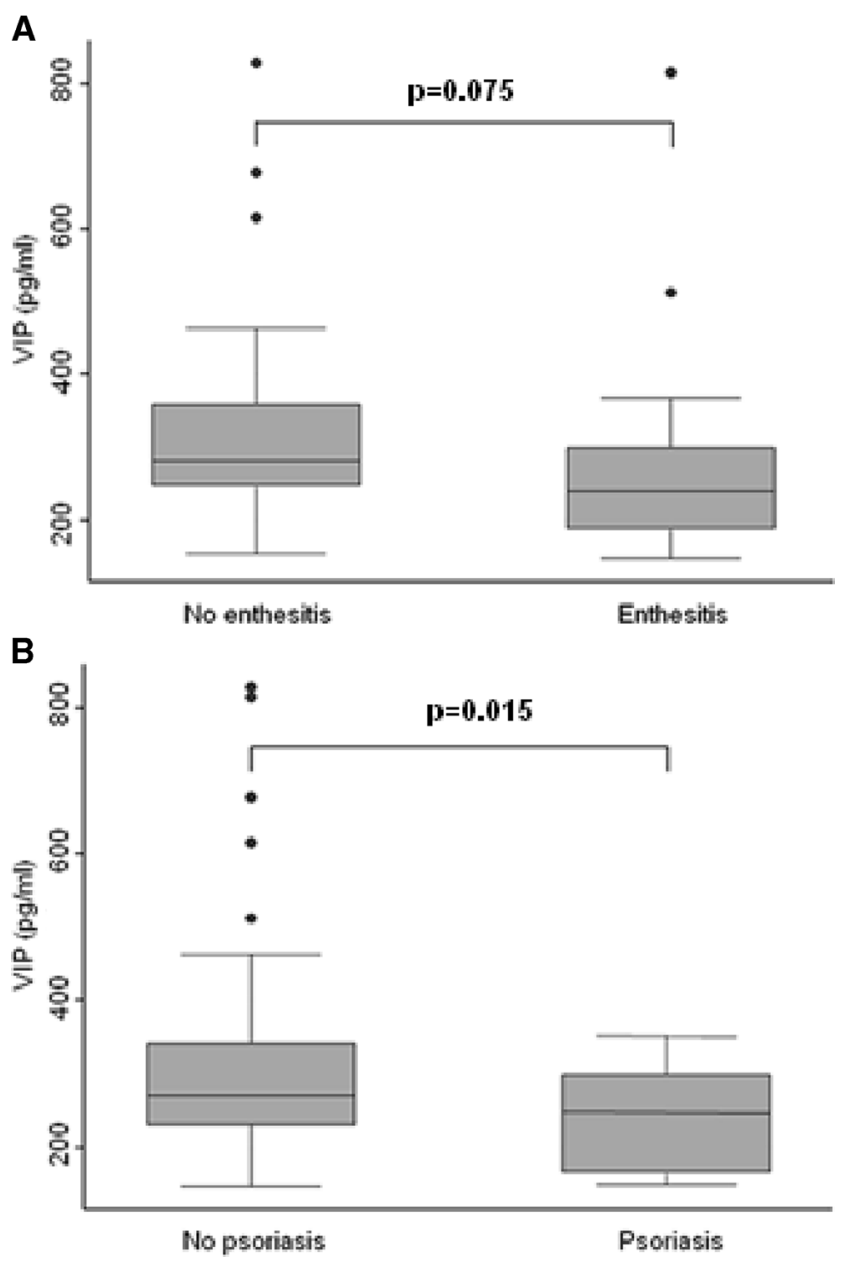

Fig. 2 Decreased VIP serum levels are associated with clinical manifestations of enthesitis (a) and psoriasis (b). The figure illustrates the association between VIP serum levels and these clinical manifestations shown at Table 2 where statistical significance is reported. Data are represented as the interquartile range (p75 upper edge of the box, p25 lower edge, p50 midline), as well as the p90 (line above the box) and p10 (line below the box) of serum VIP levels. Dots represent outliers

was not statistically significant. Conversely, we found that the correlation between VIP and uveitis contrasted with the expected trend. Nevertheless, among patients with uveitis, the patient with the highest VIP levels did not fulfill the criteria for SpA. When this patient was excluded, serum VIP levels in patients with uveitis did not exceed the median concentration in the whole population.

Drug therapy for controlling axial inflammation after failure of NSAIDs remains almost restricted to TNF blockers (van der Heijde et al. 2011); the role of DMARDs in severe peripheral forms is limited. Consequently, in recent years, one of the main objectives in the treatment of SpA has been to identify patients with an optimal safety profile and costbenefit ratio for TNF antagonists. An interesting result in our study was that treatment with anti-TNF agents seemed to increase serum VIP levels. This effect did not reach statistical
Table 3 Multivariate analysis of variables associated with VIP serum levels in patients diagnosed from spondyloarthritis

\begin{tabular}{lrll}
\hline & $\beta$ Coeff. \pm SE & CI $(95 \%)$ & $p$ value \\
\hline Enthesitis & $-0.133 \pm 0.057$ & -0.245 to 0.020 & 0.020 \\
Uveitis & $0.165 \pm 0.112$ & -0.054 to 0.385 & 0.140 \\
Psoriasis & $-0.203 \pm 0.094$ & -0.388 to -0.018 & 0.032 \\
Sacroiliitis MRI & $-0.173 \pm 0.058$ & -0.286 to -0.059 & 0.003 \\
Biological therapy & $0.175 \pm 0.123$ & -0.066 to 0.416 & 0.150 \\
BASFI & $-0.003 \pm 0.001$ & -0.006 to -0.001 & 0.017 \\
Hb $(\mathrm{g} / \mathrm{dl})$ & $0.023 \pm 0.013$ & 0.003 to 0.049 & 0.081 \\
\hline
\end{tabular}

Results of multivariate analysis performed with data from SpA patients. Only variables with $p$ value $<0.15$ in the respective bivariate analysis were included. Variables with $p$ value $<0.15$, in the respective bivariate analysis, that were not included in the final model of the multivariate analysis are as follows: age, family history of SpA, HLA-B27(+), arthritis, CRP, and ESR

$\beta$ Coeff. $\beta$ coefficient of Wald test, SE standard error, $C I$ confidence interval

significance, probably owing to the small number of patients requiring this treatment. However, it is noteworthy that we previously reported the same effect of TNF blockade on serum VIP levels in patients with RA: the increase was statistically significant, probably because of the higher number of patients treated with TNF blockers (Martinez et al. 2014). Several features point to serum VIP levels as a putative marker of the need to prescribe TNF blockers, as follows: (a) high BASFI scores and the presence of enthesitis have been identified as predictors of response to therapy with these drugs (Vastesaeger et al. 2011); (b) anemia is associated with inflammatory activity in $\mathrm{SpA}$, and improvements in hemoglobin levels have been reported after anti-TNF treatment (Furst et al. 2013; Niccoli et al. 2012); (c) low serum VIP levels have been associated with high BASFI scores and the presence of enthesitis and anemia; and (d) administration of TNF blockers increases serum VIP levels. Furthermore, it would be of particular interest to determine whether the increase in serum VIP levels reported with TNF blockers is class-specific or is also observed in autoimmune disorders treated with other biological therapies, such as blockade of interleukin (IL)- 6 or IL-12 signaling.

Our study is subject to a series of limitations. First, the sample is small, although the longitudinal design did enable us to evaluate a considerable number of observations and to better control individual variations. Second, we were unable to detect differences in VIP levels between patients with SpA and those with NLBP, even when the first visit was analyzed separately (data not shown). In addition, we have used a mixed population of patients that were finally diagnosed from $\mathrm{SpA}$ and others with NLBP. However, when patients with suspicion of $\mathrm{SpA}$ are attended for the first time at the clinic this is the challenge and establishing early a prognosis may be 
helpful despite a definite diagnosis has not been done. Nevertheless, our results were similar when analyzing the whole population or only those patients with $\mathrm{SpA}$ diagnosis.

In summary, validated biomarkers of the severity of SpA are scarce and insufficient to properly identify and classify early SpA patients according to their treatment requirements and prognosis. Consequently, new validated biomarkers are needed to achieve these goals. In this framework, the main finding of our study is that patients with early inflammatory low back pain and low serum VIP levels experience a higher inflammatory burden and worse functional outcome during the first 2 years of their disease course.

Acknowledgments The authors are grateful to the patients from the early Chronic Inflammatory Back Pain (CIBP) at Hospital Universitario La Princesa. This work was supported by the Fondo de Investigación Sanitaria, Instituto de Salud Carlos III (PI11/00195, PI11/00505, PI12/00758, RETICS RD12/0009/0002 and RD12/0009/0017 and PIE13/0051) within VI PNDE I+D+I 2008/2011 and by FEDER funds, from UCM-BSCH, and S2010/BMD-2350 from Comunidad de Madrid.

Open Access This article is distributed under the terms of the Creative Commons Attribution License which permits any use, distribution, and reproduction in any medium, provided the original author(s) and the source are credited.

\section{References}

Abad C, Martinez C, Juarranz MG et al (2003) Therapeutic effects of vasoactive intestinal peptide in the trinitrobenzene sulfonic acid mice model of Crohn's disease. Gastroenterology 124:961-971

Almodovar R, Rios V, Ocana S et al (2014) Association of biomarkers of inflammation, cartilage and bone turnover with gender, disease activity, radiological damage and sacroiliitis by magnetic resonance imaging in patients with early spondyloarthritis. Clin Rheumatol 33:237-241

Bennett AN, Rehman A, Hensor EM, Marzo-Ortega H, Emery P, McGonagle D (2009) Evaluation of the diagnostic utility of spinal magnetic resonance imaging in axial spondylarthritis. Arthritis Rheum 60:1331-1341

Braun J, Pincus T (2002) Mortality, course of disease and prognosis of patients with ankylosing spondylitis. Clin Exp Rheumatol 20:S1622

Calin A, Garrett S, Whitelock H et al (1994) A new approach to defining functional ability in ankylosing spondylitis: the development of the Bath Ankylosing Spondylitis Functional Index. J Rheumatol 21: 2281-2285

Carmona L, Ballina J, Gabriel R, Laffon A (2001) The burden of musculoskeletal diseases in the general population of Spain: results from a national survey. Ann Rheum Dis 60:1040-1045

Carrion M, Juarranz Y, Perez-Garcia S et al (2011) RNA sensors in human osteoarthritis and rheumatoid arthritis synovial fibroblasts: immune regulation by vasoactive intestinal peptide. Arthritis Rheum 63:1626-1636

Carrion M, Juarranz Y, Seoane IV et al (2014) VIP modulates IL-22R1 expression and prevents the contribution of rheumatoid synovial fibroblasts to IL-22-mediated joint destruction. J Mol Neurosci 52: $10-17$
Colbert RA, DeLay ML, Klenk EI, Layh-Schmitt G (2010) From HLAB27 to spondyloarthritis: a journey through the ER. Immunol Rev 233:181-202

Chung HY, Machado P, van der Heijde D, D’Agostino MA, Dougados M (2012) Smokers in early axial spondyloarthritis have earlier disease onset, more disease activity, inflammation and damage, and poorer function and health-related quality of life: results from the DESIR cohort. Ann Rheum Dis 71:809-816

de Vlam K (2010) Soluble and tissue biomarkers in ankylosing spondylitis. Best Pract Res Clin Rheumatol 24:671-682

Delgado M, Abad C, Martinez C, Leceta J, Gomariz RP (2001) Vasoactive intestinal peptide prevents experimental arthritis by downregulating both autoimmune and inflammatory components of the disease. Nat Med 7:563-568

Deyo RA, Weinstein JN (2001) Low back pain. N Engl J Med 344:363370

Dougados M, Baeten D (2011) Spondyloarthritis. Lancet 377:2127-2137

Fabreguet I, Koumakis E, Burki V et al (2012) Assessment of work instability in spondyloarthritis: a cross-sectional study using the ankylosing spondylitis work instability scale. Rheumatology (Oxford) 51:333-337

Furst DE, Kay J, Wasko MC et al (2013) The effect of golimumab on haemoglobin levels in patients with rheumatoid arthritis, psoriatic arthritis or ankylosing spondylitis. Rheumatology (Oxford) 52: $1845-1855$

Garrett S, Jenkinson T, Kennedy LG, Whitelock H, Gaisford P, Calin A (1994) A new approach to defining disease status in ankylosing spondylitis: the Bath Ankylosing Spondylitis Disease Activity Index. J Rheumatol 21:2286-2291

Gomariz RP, Juarranz Y, Abad C, Arranz A, Leceta J, Martinez C (2006) VIP-PACAP system in immunity: new insights for multitarget therapy. Ann N Y Acad Sci 1070:51-74

Gutierrez-Canas I, Juarranz Y, Santiago B et al (2006) VIP downregulates TLR4 expression and TLR4-mediated chemokine production in human rheumatoid synovial fibroblasts. Rheumatology (Oxford) 45:527-532

Gutierrez-Canas I, Juarranz Y, Santiago B et al (2008) Immunoregulatory properties of vasoactive intestinal peptide in human T cell subsets: implications for rheumatoid arthritis. Brain Behav Immun 22:312317

Jiang W, Gao SG, Chen XG et al (2012) Expression of synovial fluid and articular cartilage VIP in human osteoarthritic knee: a new indicator of disease severity? Clin Biochem 45:1607-1612

Jimeno R, Gomariz RP, Gutierrez-Canas I, Martinez C, Juarranz Y, Leceta $J$ (2010) New insights into the role of VIP on the ratio of T-cell subsets during the development of autoimmune diabetes. Immunol Cell Biol 88:734-745

Juarranz Y, Abad C, Martinez C et al (2005) Protective effect of vasoactive intestinal peptide on bone destruction in the collagen-induced arthritis model of rheumatoid arthritis. Arthritis Res Ther 7:R1034 1045

Kiltz U, Baraliakos X, Karakostas P et al (2012) The degree of spinal inflammation is similar in patients with axial spondyloarthritis who report high or low levels of disease activity: a cohort study. Ann Rheum Dis 71:1207-1211

Landewe R, Dougados M, Mielants H, van der Tempel H, van der Heijde D (2009) Physical function in ankylosing spondylitis is independently determined by both disease activity and radiographic damage of the spine. Ann Rheum Dis 68:863-867

Leceta J, Gomariz RP, Martinez C, Carrion M, Arranz A, Juarranz Y (2007) Vasoactive intestinal peptide regulates Th17 function in autoimmune inflammation. Neuroimmunomodulation 14:134-138

Li H, Mei Y, Wang Y, Xu L (2006) Vasoactive intestinal polypeptide suppressed experimental autoimmune encephalomyelitis by inhibiting T helper 1 responses. J Clin Immunol 26:430-437 
Lodde BM, Mineshiba F, Wang J et al (2006) Effect of human vasoactive intestinal peptide gene transfer in a murine model of Sjogren's syndrome. Ann Rheum Dis 65:195-200

Machado MADA, Barbosa MM, Almeida AM et al (2013) Treatment of ankylosing spondylitis with TNF blockers: a meta-analysis. Rheumatol Int 33:2199-2213

Machado P, Landewe RB, Braun J et al (2012) MRI inflammation and its relation with measures of clinical disease activity and different treatment responses in patients with ankylosing spondylitis treated with a tumour necrosis factor inhibitor. Ann Rheum Dis 71:2002-2005

Martinez C, Ortiz AM, Juarranz Y et al (2014) Serum levels of vasoactive intestinal Peptide as a prognostic marker in early arthritis. PLoS One 9:e85248

Marzo-Ortega H, Emery P, McGonagle D (2002) The concept of disease modification in spondyloarthropathy. J Rheumatol 29:1583-1585

Marzo-Ortega H, McGonagle D, O'Connor P et al (2009) Baseline and 1year magnetic resonance imaging of the sacroiliac joint and lumbar spine in very early inflammatory back pain. Relationship between symptoms, HLA-B27 and disease extent and persistence. Ann Rheum Dis 68:1721-1727

McGonagle D, Thomas RC, Schett G (2014) Spondyloarthritis: may the force be with you? Ann Rheum Dis 73:321-323

Nalbant S, Cagiltay E, Sahan B, Terekeci HM, Oktenli C (2011) The vasoactive intestinal polypeptide (VIP) levels at the patients with ankylosing spondylitis and its association with inflammation markers. Rheumatol Int 31:1143-1146

Niccoli L, Nannini C, Cassara E, Kaloudi O, Cantini F (2012) Frequency of anemia of inflammation in patients with ankylosing spondylitis requiring anti-TNFalpha drugs and therapy-induced changes. Int $\mathrm{J}$ Rheum Dis 15:56-61
Pan W (2001) Model selection in estimating equations. Biometrics 57: 529-534

Poddubnyy D, Haibel H, Listing J et al (2012) Baseline radiographic damage, elevated acute-phase reactant levels, and cigarette smoking status predict spinal radiographic progression in early axial spondylarthritis. Arthritis Rheum 64:1388-1398

Rudwaleit M, Jurik AG, Hermann KG et al (2009a) Defining active sacroiliitis on magnetic resonance imaging (MRI) for classification of axial spondyloarthritis: a consensual approach by the ASAS/OMERACT MRI group. Ann Rheum Dis 68:1520-1527

Rudwaleit M, Khan MA, Sieper J (2005) The challenge of diagnosis and classification in early ankylosing spondylitis: do we need new criteria? Arthritis Rheum 52:1000-1008

Rudwaleit M, van der Heijde D, Landewe R et al (2009b) The development of Assessment of SpondyloArthritis international Society classification criteria for axial spondyloarthritis (part II): validation and final selection. Ann Rheum Dis 68:777-783

van der Heijde D, Sieper J, Maksymowych WP et al (2011) 2010 Update of the international ASAS recommendations for the use of anti-TNF agents in patients with axial spondyloarthritis. Ann Rheum Dis 70: 905-908

van der Linden S, Valkenburg HA, Cats A (1984) Evaluation of diagnostic criteria for ankylosing spondylitis. A proposal for modification of the New York criteria. Arthritis Rheum 27:361-368

Vastesaeger N, van der Heijde D, Inman RD et al (2011) Predicting the outcome of ankylosing spondylitis therapy. Ann Rheum Dis 70: 973-981

Ward MM, Learch TJ, Gensler LS, Davis JC Jr, Reveille JD, Weisman MH (2013) Regional radiographic damage and functional limitations in patients with ankylosing spondylitis: differences in early and late disease. Arthritis Care Res (Hoboken) 65:257-265 